\title{
NIETZSCHE: UNA INFLEXIÓN DECISIVA EN EL PAÍ́S DE LA DISCONTINUIDAD
}

Nietzsche: a decisive inflection in the country of discontinuity

\author{
Manuel Barrios Casares
}

Universidad de Sevilla

Resumen: Se revisa el estado anterior de la recepción de la obra de Nietzsche en España, tanto en lo referente a ediciones como a interpretaciones de su pensamiento, y se argumentan los motivos por los que los recientes proyectos de edición de sus Fragmentos Póstumos y Obras Completas constituyen un hito esencial en la consolidación de una investigación especializada en nuestro país.

Palabras clave: Nietzsche - Historia de la recepción - Edición crítica - Hermenéutica Traducción

ABSTRACT: The previous status of the reception of Nietzsche's work in Spain is reviewed, both in terms of editions and interpretations of his thought. The reasons why the recent editing projects of their Posthumous Fragments and Complete Works are an essential milestone in the consolidation of a specialized research in our country are argued.

Keywords: Nietzsche - History of the reception - Critical edition - Hermeneutics Translation

Nietzsche gustó de presentarse a menudo como el pensador de la gran ruptura con la tradición. Pero lo cierto es que, tras haber tomado distancia de las hipotecas románticas de su filosofía de juventud y haber abandonado la quimera de una salida metafísica a la decadencia de su tiempo, siempre mantuvo desde entonces una clara conciencia de que el oleaje del pasado no deja nunca de seguir golpeando las costas del presente (VM, 223), prestándole matices, dejando ciertas huellas, provocando reacciones y, en suma, ayudando a cincelar su perfil más propio; y así nos enseñó que todo germen de novedad surge solo a partir de una asunción recreadora de lo heredado, aun cuando sea por vía de contraste. En ese mismo sentido, no sería posible valorar en su justa medida lo que han supuesto para la cultura hispanoparlante los recientes proyectos de edición en castellano de los Fragmentos Póstumos y las Obras Completas de Nietzsche, llevados a cabo por el equipo de investigación dirigido por el profesor Diego Sánchez Meca, junto al de la Correspondencia, a cargo del profesor Luis Enrique de Santiago Guervós, sin contextualizarlos mínimamente dentro de lo que ha sido la historia de la recepción de Nietzsche en España. Únicamente así cabe apreciar en todo su alcance hasta qué punto estos proyectos han sido capaces al fin, después de tantas tentativas aisladas, dispersas y carentes de la suficiente consistencia, de dar respuesta 
satisfactoria a la demanda de ofrecer al lector en nuestra lengua el conjunto de la obra nietzscheana en una versión filológicamente fiable.

Si los especiales avatares de los escritos de Nietzsche -manipulados in extenso por su abusiva hermana y durante casi sesenta años accesibles tan solo de manera sesgada y equívoca, fundamentalmente a través de la Grossoktavausgabe ${ }^{1}$ pudieron ir hallando su debida enmienda a partir de 1967, con la nueva edición crítica de sus obras completas emprendida por Giorgio Colli y Mazzino Montinari ${ }^{2}$, en España e Hispanoamérica hubo que esperar otros cuarenta y tantos años más hasta contar con un equivalente a la altura de los resultados científicos cosechados por aquel relevante empeño editorial y sus secuelas. Probablemente, esta ausencia de una edición crítica completa de las obras del filósofo sea uno de los factores que explica el que, en el caso del contexto hispano, se haya prolongado más que en el de otras lenguas europeas un tipo de lectura de Nietzsche más ensayística que sistemática, menos interesada en la reconstrucción rigurosa de su pensamiento que en rentabilizar la eficacia intempestiva de algunas de sus ideas, lectura que fue típica de las primeras etapas de recepción de su obra.

En efecto: tal como sucediera en el resto de la cultura europea, la primera acogida de Nietzsche en España fue debida a literatos, artistas y amateurs en cuestiones filosóficas antes que a académicos y expertos en filosofía ${ }^{3}$. En un artículo pionero de 1893, Joan Maragall profetizaba que pronto ese «sociólogo artista» estaría de moda en nuestro país como antídoto contra la decadencia. Y así ocurrió. Modernistas como Rubén Darío o Valle-Inclán se sintieron contagiados por su inmoralismo, pese a no llegar nunca a adoptarlo en toda su radicalidad; y, sobre todo, los escritores de la llamada «Generación del 98» lo leyeron con especial interés, interpelados por su combativa actitud frente a la epidemia de nihilismo que azotaba el fin de siglo. Fueron ellos quienes trasladaron muchas de sus ideas e inquietudes a los personajes y situaciones de su producción novelística. No hubo en aquel contexto de crisis y declive nacional un tratamiento detallado y riguroso de su obra, sino una difusa asimilación de aspectos aislados de su filosofía, mezclados con acentos schopenhauerianos y proclamas vitalistas. Se entiende así que, en medio de aquella imprecisa recepción, Nietzsche pudiera servir de estímulo tanto a socialistas y anarquistas como a conservadores. Unos aprovechaban su crítica de los valores morales como complemento de sus consignas anticlericales y antimilitaristas, mientras que otros apelaban a la moral de señores para prestigiar su defensa del autoritarismo. De una línea a otra transitarían figuras como Ramiro de Maeztu. Era la nueva generación en su conjunto la que sintonizaba con el ímpetu renovador del mensaje profético del Zaratustra, más afín en el tono a las queren-

1. Friedrich Nietzsche, Werke. Grossoktavausgabe, Leipzig: Kröner, 1905 ss. (20 vols.).

2. Friedrich Nietzsche, Werke. Kritische Gesamtausgabe (= KGW), ed. de G. Colli y M. Montinari, Berlin: Walter de Gruyter, 1967 ss.

3. Para una visión pormenorizada de esta recepción, vid. Gonzalo Sobejano, Nietzsche en España, Madrid: Gredos, 1967; así como Udo Rukser, Nietzsche in der Hispania. Ein Beitrag zur hispanischen Kultur und Geistesgeschichte, Bern/München: Francke, 1962. Para la recepción más reciente, vid. Diego Sánchez Meca, «Nietzsche en España», en M. Garrido, N. Orringer, L. y M. Valdés (coords.), El legado filosófico español e hispanoamericano del siglo xx, Madrid: Cátedra, 2009, espec. pp. 959-971; y Marco Parmeggiani y Eduardo Fava, «Nietzsche en España», en D. Sánchez Meca y J. Conill (eds.), Guía Comares de Nietzsche, Granada: Comares, 2014, pp. 285-312. 
cias de Azorín, Baroja o Maeztu que a las del «viejo» Unamuno, por muy filtrado por Schopenhauer que apareciese todo este primer nietzscheanismo hispano. La falta de traducciones fiables - solían ser en su mayoría versiones del francés y comenzaron a aparecer a partir de 1900- imposibilitaba un contraste con las ideas del filósofo menos saturado de forzadas mediaciones interpretativas.

Solo Ortega y Gasset procuró conferir mayor solidez a su lectura de la obra nietzscheana, a la que tuvo acceso ya desde su primera estancia en Alemania, entre 1905 y 1907. Sin embargo, su afán polémico contra los «Hércules bárbaros» ${ }^{4}$ del noventayochismo, primero, y su prurito de originalidad, después, le impidieron alcanzar una confrontación realmente clarificadora de esta importante deuda intelectual. Ortega fue, sin duda, como bien subrayara Gonzalo Sobejano en su relevante monografía Nietzsche en España, el pensador de la generación del 14 en quien la influencia nietzscheana resultó «más extensa, intensa y trascendental» ${ }^{5}$. A pesar de ello, a pesar de todo cuanto el pensamiento orteguiano de los años veinte siguió debiendo a Nietzsche, el deseo insistente de Ortega de marcar diferencias - y, a partir de 1929, de presentarse como un filósofo sistemático con una nueva propuesta metafísica antes que como un mero crítico de la culturallevó a desfigurar los términos de esta relación, a desatenderla en gran medida y, con ello, a desconocer el verdadero alcance de la incidencia de Nietzsche en la cultura española de la primeras décadas del siglo XX. Oscurecido este hilo conductor, quebrado también el enlace con la propia tradición filosófica española a raíz de la Guerra Civil, el nietzscheísmo hispano, que en su primera aparición en nuestras latitudes había adoptado un perfil más progresista y revolucionario, acabó convertido en cosa de literatos (D’Ors, Gómez de la Serna, Pérez de Ayala, Bergamín), cuando no limitado a las formas de un individualismo aristocrático cada vez más conservador, $y$, en términos generales, marginado, sin apenas presencia entre los representantes de la filosofía oficial. De 1939 a comienzos de los años sesenta del siglo pasado esa desafección no hizo sino acentuarse, hasta el punto de llevar a Sobejano a concluir su volumen de 1967, dedicado a rastrear la incidencia del pensamiento nietzscheano en nuestro país, con estas palabras:

Las promociones jóvenes españolas están muy lejos de Nietzsche. Entre los grandes forjadores del mundo espiritual moderno - Marx, Nietzsche- prefieren al primero. Y no es extraño que así ocurra. Poniendo aparte todas las virtudes eminentes de Nietzsche como metafísico, crítico de la cultura y de la moral, psicólogo y poeta, su influencia ha sido uno de los elementos primordiales que han encaminado a España a una situación que ahora se revela insatisfactoria: la voluntad se hizo violencia, la aristocracia desembocó en autoritarismo, el individualismo en anarquía fracasada, la glorificación de la vida en desesperación respecto al sentido humano y solidario de la vida 6 .

De este modo, Sobejano venía a asociar la interpretación de Nietzsche dominante en España a lo largo de toda la primera mitad del siglo xx con la convulsión que había llevado a la Guerra Civil y con la posterior deriva reaccionaria que había supuesto el régimen franquista. Poco podía imaginar que en poco

4. José Ortega y Gasset, Obras Completas, Madrid: Revista de Occidente, 1966, vol. IX, 494.

5. G. Sobejano, op. cit., p. 527.

6. Ibid., p. 664. 
tiempo cambiara tanto el panorama, que a comienzos de los setenta buena parte de los jóvenes filósofos españoles dejara de preferir a Marx y se entusiasmara con Nietzsche, leyéndolo en un registro bien distinto, más vinculado al pensamiento rebelde y contestatario de los nuevos tiempos que al viejo autoritarismo. Fue la generación de jóvenes y brillantes ensayistas como Eugenio Trías (1942) o Fernando Savater (1947) la que protagonizó este cambio. Como ha relatado oportunamente Francisco Vázquez García en su estudio Hijos de Dionisos ${ }^{7}$, estos autores constituyeron una verdadera bohemia intelectual, singularizada al rechazar tanto la filosofía académica de las universidades tardofranquistas como las alternativas «serias», representadas en aquel entonces por la filosofía analítica y el marxismo. No practicaban un comentario erudito de Nietzsche, sino que se lo reapropiaban en la estela de la vanguardia filosófica francesa del momento (Foucault, Deleuze, Bataille, Klossowski, etc.) para ejercer una crítica cultural de nuevo cuño. Este nietzscheísmo hispano, asociado en parte a otros movimientos subsiguientes como el de la posmodernidad, se hizo sitio en la escena intelectual y acumuló prestigio al atacar mordazmente a las opciones rivales y al difundirse en formas distintas a las oficiales (artículos de prensa, tertulias, etc.). Burlándose del reproche descalificatorio de irracionalismo que neoescolásticos, marxistas y analíticos coincidieron en asignarles, pusieron de manifiesto cómo sin una crítica de la razón, de la metafísica y la cultura modernas como la emprendida por Nietzsche, cómo sin un careo con la problemática del nihilismo, la filosofía estaba condenada a languidecer como una simple guardiana nostálgica de los sistemas periclitados del pasado, sin genuino nervio para medirse con el presente y esclarecerlo de modo crítico.

No obstante, al margen de su invocación estratégica de Nietzsche, estos autores, de innegable talento literario y filosófico, se hallaban más interesados en desarrollar un pensamiento propio que en realizar un comentario erudito de la filosofía nietzscheana. Así que no llegaron a cuajar grandes interpretaciones sistemáticas de su obra ${ }^{8}$. La confluencia episódica con alguien procedente del círculo de jóvenes católicos aperturistas de los sesenta, formados teológicamente en el mundo germánico, como era Andrés Sánchez Pascual, que traducía entonces la obra publicada de Nietzsche y empezaba ya a anunciar su siempre postergada traducción íntegra de los fragmentos póstumos del filósofo, pudo sugerir por un tiempo la impresión de que en ese contexto se iban a generar los mejores frutos de la nueva recepción de Nietzsche en España. El emblemático volumen colectivo En favor de Nietzsche (1972) ${ }^{9}$ parecía anunciarlo. No fue exactamente así.

Por otra parte, tampoco resulta del todo exacta la sugerencia de Francisco Vázquez, cuando, queriendo establecer un paralelismo con la polaridad existente entonces en Francia entre un enfoque erudito de Nietzsche, al estilo de Jean Granier, y un tratamiento vanguardista, al modo de Deleuze, sostiene que en España, en aquel momento, ese trabajo académico más serio y concienzudo con los textos

7. Francisco Vázquez García, Hijos de Dionisos. Sociogénesis de una vanguardia nietzscheana (1968-1985, Madrid, Biblioteca Nueva, 2014.

8. El texto más completo en este sentido fue el de Fernando Savater, Conocer Nietzsche y su obra, Barcelona: Dopesa, 1977.

9. AA. VV., En favor de Nietzsche, Madrid: Taurus, 1972. En él colaboraron Eugenio Trías, Fernando Savater, Santiago González Noriega, Pablo Fernández Flórez, Ángel González, Ramón Barce, Javier Echeverría y Andrés Sánchez Pascual. 
nietzscheanos fue satisfecho por aquellos jóvenes representantes del catolicismo teológicamente avanzado que él cita en su artículo sobre la recepción de Nietzsche en el campo filosófico del tardofranquismo: Alfonso Álvarez Bolado, Andrés Sánchez Pascual y Luis Jiménez Moreno ${ }^{10}$. La realidad es que, de ellos, solo este último publicó en aquellos años un libro sobre el pensador del eterno retorno. Fue concretamente en 1972, ocho años después de la lectura de su tesis doctoral en la Universidad Complutense, El pensamiento antropológico de Nietzsche, de contenido y alcance más bien discretos ${ }^{11}$. Por su parte, Sánchez Pascual jamás publicó una monografía sobre Nietzsche, solo la serie de estudios introductorios que acompañan a sus traducciones en Alianza Editorial. Y en cuanto a Álvarez Bolado, tras su tesis doctoral sobre Nietzsche y Heidegger tampoco se prodigó mucho más en ese sentido.

El verdadero impulso a la investigación sobre Nietzsche en España y, con ella, a una exégesis rigurosa de su filosofía, libre de las mixtificaciones del pasado y las remitificaciones del presente, fue fundamentalmente obra de profesores universitarios de una generación más joven que, al filo de los años ochenta, comenzaron a publicar los resultados de su escrupuloso trabajo de lectura, traducción, contextualización e interpretación de todo el conjunto del corpus nietzscheano. Entre esos estudiosos destacarían en primer lugar Joan Bautista Llinares, Remedios Ávila, Juan Luis Vermal y Diego Sánchez $\mathrm{Meca}^{12}$. A ellos se sumarían pronto Luis Enrique de Santiago Guervós, Jesús Conill y quien esto suscribe ${ }^{13}$, con la incorporación posterior de Marco Parmeggiani ${ }^{14}$, constituyendo así por primera vez un sólido núcleo de investigación especializada sobre Nietzsche en nuestro país. Característica común de la labor desarrollada por estos estudiosos era el trato directo con los textos originales en alemán, la referencia insistente al Nachlass,

10. F. Vázquez García, «La recepción de Nietzsche en el campo filosófico del tardofranquismo: el caso de Fernando Savater (1970-1974)»: Estudios Nietzsche 11 (2011), pp. 127-143. Cf. pp. 128-131.

11. Sí que es justo reconocer, sin embargo, que Jiménez Moreno mantuvo viva su dedicación a Nietzsche con la publicación de alguna monografía de contenido introductorio (El pensamiento de Nietzsche, Madrid: Cincel, 1986; Friedrich Nietzsche (1844-1900), Madrid: Ediciones del Orto, 1995) y, sobre todo, artículos y colaboraciones en volúmenes colectivos.

12. Joan Bautista Llinares, Hombre, arte y lenguaje. Una investigación sobre el joven Nietzsche, Valencia: Servei de Publicacions de la Universitat de València, 1982; Remedios Ávila Crespo, Nietzsche y la redención del azar, Universidad de Granada, 1986; Juan Luis Vermal, La crítica de la metafísica en Nietzsche, Barcelona: Anthropos, 1987; Diego Sanchez Meca, En torno al superhombre. Nietzsche y la crisis de la modernidad, Barcelona: Anthropos, 1989. En esos años también publicaba Julio Quesada Un pensamiento intempestivo. Ontología, estética y política en Nietzsche, Barcelona: Anthropos, 1988.

13. Manuel Barrios, La voluntad de poder como amor, Barcelona: Ediciones del Serbal, 1990 (2. ${ }^{a}$ ed., con prólogo de E. Trías, Madrid: Arena Libros, 2006); Hölderlin y Nietzsche, dos paradigmas intempestivos de la modernidad en contacto, Sevilla: Reflexión, 1992; Voluntad de lo trágico. El concepto nietzscheano de voluntad a partir de 'El nacimiento de la tragedia', Sevilla: Er, 1993 (2. ed., Madrid: Biblioteca Nueva, 2002); Narrar el abismo, Valencia: Pre-Textos, 2000; Jesús Conill, El poder de la mentira. Nietzsche y la politica de la transvaloración, Madrid: Tecnos, 1997; Luis E. de Santiago, "Nietzsche y los límites del lenguaje: la fuerza del instinto», en Íd. (ed.), Actualidad de Nietzsche, Universidad de Málaga, 1994; "El poder de la palabra», en F. Nietzsche, Escritos sobre retórica, Madrid: Trotta, 2000; Arte y poder. Aproximación a la estética de Nietzsche, Madrid: Trotta, 2004

14. M. Parmeggiani, Perspectivismo y subjetividad en Nietzsche, Universidad de Málaga, 2002; Nietzsche: crítica y proyecto desde el nihilismo, Málaga: Ágora, 2002. 
hasta entonces poco frecuentado entre los intérpretes hispanos de Nietzsche, el amplio conocimiento de la literatura secundaria en otras lenguas y el interés por los aspectos más propiamente filosóficos del pensamiento nietzscheano, a fin de lograr una visión íntegra de su trayectoria intelectual. Para todos ellos, la interpretación filosófica de Nietzsche pasaba por un análisis histórico-crítico de su obra, conscientes de que solo comprendiendo la evolución de sus ideas y contextualizándolas en la red de lecturas e influencias de su época sería posible dotar de coherencia y claridad a un pensar tan poco dado a la sistematicidad como el nietzscheano. Todos ellos, además, fueron autores de destacadas monografías sobre Nietzsche y han seguido profundizando en las ideas de este pensador con publicaciones en revistas científicas y colaboraciones en volúmenes colectivos, así como con intervenciones en congresos y seminarios especializados, hasta homologar su producción en el campo de los estudios nietzscheanos con la investigación a nivel europeo y mundial. Por primera vez, ahora sí, la Nietzsche-Forschung podía hallar en lengua castellana trabajos a la altura de los del resto de la comunidad científica internacional, capaces de entablar un debate científico sobre cuestiones eruditas en pie de igualdad. Al mismo tiempo, en no pocos casos, esta literatura especializada en castellano acertaba a incorporar provechosamente, aunque fuese en un registro más académico, algunos de los valiosos frutos del feliz ensayismo neonietzscheano practicado por Trías o Savater.

Pero lo aportado por este grupo generacional a un cambio de marcha en la recepción de Nietzsche en España ha sido mucho más. Por iniciativa de Luis Enrique de Santiago Guervós y Diego Sánchez Meca, en el año 2000, conmemorativo del centenario de la muerte del filósofo, se fundaba la Sociedad Española de Estudios sobre Nietzsche (SEDEN) como plataforma para ofrecer un lugar de encuentro y dar soporte a la investigación especializada sobre este autor, tanto a través de la organización de congresos y seminarios como mediante la publicación de la revista científica indexada Estudios Nietzsche (2001 ss.) ${ }^{15}$. De esta forma se establecían las bases para una continuidad intergeneracional en el trabajo de análisis e interpretación del pensamiento nietzscheano, que hasta aquel momento había faltado en nuestro país. Queriendo simbolizar dicha continuidad, la conferencia inaugural del primer congreso internacional de la SEDEN, celebrado en la Universidad de Málaga en 2008, fue impartida por Eugenio Trías, quien apoyó con entusiasmo estos proyectos y colaboró además en el primer número de la revista, en cuyas páginas habrían de ir apareciendo también referencias puntuales a las contribuciones de Savater, Miguel Morey, Enrique Lynch y otros antecesores, así como a las de quienes han venido después: Elvira Burgos, José Emilio Esteban, Mariano Rodríguez, Encarnación Ruiz, Germán Cano o José Manuel Romero Cuevas, por citar solo algunos nombres conocidos ${ }^{16}$. Se fue logrando así cohesionar una comunidad de

15. Un anuncio de esta iniciativa tuvo lugar en julio del año 2000 durante un curso de verano de la UNED en Segovia titulado «Nietzsche y la filosofía: nuevas perspectivas y nuevas interpretaciones». Dirigido por Diego Sánchez Meca, contó con la participación de Luis de Santiago, Joan Llinares, Julio Quesada, Germán Cano y la mía propia. Vid. al respecto la reseña del volumen II de los Fragmentos Póstumos a cargo de Antonio Morillas en La Torre del Virrey. Revista de Estudios Culturales, Tercera Serie, verano de 2009, p. 1.

16. E. Burgos, Dioniso en la filosofía del joven Nietzsche, Zaragoza: Prensas Universitarias, 1993; J. E. Esteban, Politica y cultura en el pensamiento del joven Nietzsche (1869-1876), Madrid: 
estudiosos de Nietzsche en España. De ahí partió entonces la iniciativa de superar otra de las asignaturas pendientes para la investigación en nuestra lengua: hasta finales del siglo veinte, los lectores hispanohablantes seguían sin disponer de una versión en castellano equivalente a lo ofrecido por las ediciones críticas en alemán de las obras del filósofo, su correspondencia o sus cuadernos de trabajo. Había ediciones de algunos de los libros publicados por Nietzsche en vida, de calidad muy desigual, siendo las más apreciadas las traducciones firmadas por Sánchez Pascual. Pero en cuanto a obras completas, se seguía acudiendo a las así mal llamadas que Eduardo Ovejero y Mauri había editado en Aguilar durante los años 1932-1933, basándose en la Grossoktavausgabe, una edición bastante defectuosa en general y en particular en el apartado relativo a textos inéditos y borradores de trabajo. Fue iniciativa de Diego Sánchez Meca abordar una traducción completa de los fragmentos póstumos, como parte del plan más ambicioso de ofrecer por fin en castellano una edición íntegra fiable de los escritos nietzscheanos, tal como las existentes desde hacía años en otras lenguas europeas.

Quienes tuvimos la suerte de participar en este doble proyecto de edición de los fragmentos póstumos y las obras completas de Nietzsche, contrajimos una impagable deuda de gratitud con el profesor Diego Sánchez Meca. Él supo crear un verdadero equipo de investigación y orientó nuestra labor de exégesis de los textos nietzscheanos en un sentido de lo más provechoso no solo para nuestra pequeña comunidad intelectual, hecha de cien profundas soledades y alguna que otra honda amistad, sino para el conjunto de la comunidad filosófica española y la cultura hispanoparlante en general, entregándole un trabajo del que hay que decir, sin falsa modestia, que ha sido capaz de alcanzar un nivel de excelencia dentro de la investigación especializada sobre Nietzsche equiparable al existente en esos países vecinos que hace unos años iban muy por delante de nosotros en este apartado.

Ya han sido sugeridas antes, de pasada, algunas de las claves que explican este óptimo resultado. Acudiendo a los términos de la sociología histórica de la filosofía empleados por Francisco Vázquez García, podría decirse que este grupo recibió en su juventud el estímulo de la lectura vanguardista de los neonietzscheanos de los sesenta, procurando transmitir luego algo del aire ensayístico y poco dogmático de aquellos autores a su propia tarea de comentario erudito de Nietzsche. Por eso su abordaje de cuestiones nietzscheanas fue desde el principio de lo más amplio y abierto, involucrando otros campos de las ciencias humanas dentro del registro filosófico más convencional: metafísica, teoría del conocimiento, ética, estética, filosofía política, filosofía del lenguaje, pero también retórica, filología, crítica de la cultura, teoría crítica... Contaban además con un conocimiento bastante exhaustivo del universo Nietzsche, lo habían leído e interpretado durante años antes de dedicarse sistemáticamente a la traducción de sus escritos.

UAM, 1999; El joven Nietzsche. Política y tragedia, Madrid: Biblioteca Nueva, 2004; M. Rodríguez, La teoría nietzscheana del conocimiento, Madrid: Eutelequia, 2010; El sujeto velado: A partir de Nietzsche y Wittgenstein, Madrid: Biblioteca Nueva, 2010; G. Cano, Como un ángel frío. Nietzsche y el cuidado de la libertad, Valencia: Pre-Textos, 2000; Nietzsche y la crítica de la modernidad, Madrid: Biblioteca Nueva, 2001; J. M. Romero, El caos y las formas. Experiencia, conocimiento y verdad en F. Nietzsche, Granada: Comares, 2001; E. Ruiz, Nietzsche y la filosofía práctica. La moral aristocrática como búsqueda de la salud, Universidad de Granada, 2004. 
De manera que estaban en la mejor disposición para abordar una empresa de tal envergadura. En ese mismo sentido, otro dato relevante y poco conocido es el hecho de que el grupo venía trabajando ya en los preparativos para su edición desde cinco años antes de la concesión del primero de los cuatro proyectos de investigación del Plan Nacional de I+D que estuvieron dedicados a esta labor. Especialmente intensa fue su dedicación en esos años preliminares a la confección de un extenso glosario de términos, con sus posibles variantes de traducción. Se generó de este modo una buena base común de colaboración entre un conjunto de especialistas disperso por toda la geografía universitaria nacional, pero cohesionado en cuanto a formación previa en la materia, metodología y empeño filosófico. El tratamiento dado al glosario puede servir de inmejorable ejemplo del modo escrupuloso de abordar sus traducciones por parte de este grupo, un modo que ha procurado ser flexible sin caer en la arbitrariedad, riguroso sin volverse rígido, y en el que, una vez establecido el campo semántico de cada término, los distintos traductores se han permitido ligeras variantes en función de los diferentes contextos y sentidos, pero siempre de manera coherente con el léxico de referencia. Partiendo del índice general de términos contenido en la Kritische Studienausgabe ${ }^{17}$ y teniendo en cuenta asimismo contribuciones posteriores de la investigación erudita como el Nietzsche-Handbuch, el Nietzsche-Wörterbuch o el Nietzsche-Lexikon, fueron aquilatando este aspecto como una de las principales tareas preparatorias ${ }^{18}$.

A partir de ahí se abordó en una primera fase, durante los seis años siguientes, la edición de los Fragmentos póstumos (= FP). Publicados en cuatro volúmenes por la editorial Tecnos entre 2006 y $2010^{19}$, se puso a disposición del lector hispano una edición íntegra de este material, tomando como base textual la edición crítica Colli-Montinari e incorporando paulatinamente las correcciones de los Nachberichte (informes y comentarios filológicos adicionales) y otros resultados de la Nietzsche-Forschung. En paralelo, bajo la dirección de Luis Enrique de Santiago, la editorial Trotta publicaba la correspondencia completa y anotada de Nietzsche en seis volúmenes entre 2005 y 2012. Así, a comienzos de esta década el público hispanohablante pudo asomarse por fin a contemplar en su conjunto el «taller de Nietzsche», como acertadamente lo designó el también estudioso y traductor del filósofo, Luis Fernando Moreno Claros, en una positiva reseña de los dos primeros volúmenes de póstumos: «decenas de cuadernos y cartapacios llenos de anotaciones entre las que se encuentran cientos de aforismos,

17. F. Nietzsche, Werke. Kritische Studienausgabe, ed. de G. Colli y M. Montinari, 15 vols., Berlin: Walter de Gruyter, 1980 ( $\left.{ }^{3} 1999\right)$.

18. Henning Ottmann, Nietzsche-Handbuch, Stuttgart: Metzler, 2000; Paul van Tongeren, Gerd Schank y Herman Siemens (eds.), Nietzsche-Wörterbuch, 4 vols., Berlin: De Gruyter, 2001 ss.; Christian Niemeyer (ed.), Nietzsche-Lexikon, Darmstadt: Wissenschaftliche Buchgesellschaft, 2012.

19. F. Nietzsche, Fragmentos póstumos (1869-1874), Madrid: Tecnos, 2007 (2. ${ }^{\mathrm{a}}$ ed. corregida y aumentada, 2010): FP II (1875-1882), 2008; FP III (1882-1885), 2010; FP IV (1885-1889), 2006. Como puede comprobarse por estas referencias, en primer lugar se publicó el último volumen, considerado el más atractivo para el gran público al contener los inéditos correspondientes al proyecto de una obra sistemática titulada La voluntad de poder. Ensayo de una transvaloración de todos los valores, finalmente abandonada por Nietzsche pero reconstruida de modo bastante arbitrario por Peter Gast y Elisabeth Förster-Nietzsche. 
pensamientos y esbozos; en conjunto, un complemento idóneo para profundizar en la comprensión de los textos publicados por Nietzsche» ${ }^{20}$.

Además de la traducción fiel del texto, la edición venía acompañada de unos extensos estudios preliminares, un exhaustivo aparato crítico de notas y una detallada cronología. Y con los mismos criterios se abordaba ya en 2008 la edición de las Obras Completas (= OC), que aparecieron publicadas igualmente en cuatro volúmenes entre 2011 y $2016^{21}$. El equipo ya consolidado de investigadores participantes en este proyecto estuvo formado por los profesores Jaime Aspiunza (Universidad del País Vasco), Manuel Barrios (Universidad de Sevilla), Jesús Conill (Universidad de Valencia), Joan B. Llinares (Universidad de Valencia), Luis E. de Santiago (Universidad de Málaga), Marco Parmeggiani (Universidad de Málaga), Juan Luis Vermal (Universidad de las Islas Baleares) y Diego Sánchez Meca (UNED). Las traducciones se basaron en los textos establecidos por Colli y Montinari a partir de los manuscritos y ediciones de obras de Nietzsche, tal como dichos textos resultan accesibles hoy día en la nueva edición digital, la eKGWB, disponible en la web de acceso libre http://www.nietzschesource.org: una edición electrónica fruto del espléndido trabajo del grupo de investigación internacional HyperNietzsche, dirigido por Paolo D'Iorio ${ }^{22}$, que incorpora directamente al texto digitalizado todas las correcciones filológicas contenidas en los diversos volúmenes de comentarios de la edición impresa, siendo por tanto la mejor y más actualizada versión del texto crítico. Completando la edición crítica alemana con criterios propios en cuanto a metodología y resultados de investigación, incorporando además gran cantidad de materiales juveniles inéditos y el grueso principal de sus escritos filológicos, esta edición castellana de las obras de Nietzsche ha venido así a ofrecer un producto de excelencia por su rigor, pulcritud y exhaustividad, sobrepujando a las ediciones existentes en otras grandes lenguas de la cultura europea (francés, italiano, inglés).

No cabe duda de que con toda esta aportación se ha posibilitado una nueva manera de leer a Nietzsche en castellano mucho más solvente y comprehensiva ${ }^{23}$. De forma muy sintética, esbozaremos tan solo algunas muestras de ello. Cabe comenzar señalando, por ejemplo, cómo ya desde el título mismo de algunas de las principales obras de Nietzsche se puede apreciar hasta qué punto una traducción rigurosa ayuda a una buena interpretación y viceversa. Es el caso de la decisión de Aspiunza de recuperar la preposición zur del título alemán de Zur Genealogie der Moral y traducirlo por De la genealogía de la moral. Pues, como argumenta con razón, mientras que «el título habitual de La genealogía... nos hace pensar en una obra definitiva, acabada y completa sobre dicho asunto, la corrección que opera el De la... o el Sobre la... (que corresponde al peri griego o al de latino) hace que cambie por completo el sentido: los tres ensayos no constituyen la genealogía,

20. L. F. Moreno Claros, «El taller de Nietzsche», en Babelia. Suplemento cultural de El País, 14 de abril de 2007, p. 12.

21. F. Nietzsche, Obras Completas I: Escritos de juventud, Madrid: Tecnos, 2011; OC II: Escritos filológicos, 2013; OC III: Obras de madurez I, 2014; OC IV: Escritos de madurez II y Complementos a la edición, 2016.

22. Cf. P. D'Iorio, HyperNietzsche, Paris: PUF, 2000.

23. Un espléndido ejemplo de este nuevo contexto hermenéutico lo acaba de publicar Diego Sánchez Meca: El itinerario intelectual de Nietzsche, Madrid: Tecnos, 2018. 
son aportaciones a ella» (OC IV, 443-444). Otro tanto sucede con el subtítulo de Ecce Homo. Eduardo Ovejero y Mauri tradujo ese Wie man wird, was man ist por «Cómo se llega a ser lo que se es» y tanto Andrés Sánchez Pascual como otros muchos mantuvieron esa traducción. Aun pudiendo parecer correcta, no acababa de convencernos. En alemán, la fórmula es impersonal (man), no reflexiva (sich), y, además, Nietzsche no dice cómo llega a uno a ser quien (wer) es, sino lo que (was) es... ¿Son detalles insignificantes? No lo creemos así. Hay un problema al añadir esa reflexividad a la fórmula, y es que invita a pensar ese devenir (wird), ese «llegar a ser» o «convertirse» en algo según el modelo de la reflexividad moderna, hegeliana podríamos decir: cómo llega uno a ser para sí lo que ya de suyo es en sí desde el principio; lo cual sería tanto como decir cómo realiza uno plenamente lo que ya era en potencia. Pero Nietzsche no dice esto. No es el despliegue de una esencia preexistente hasta su plenitud autoconsciente lo que relata su singular autobiografía. Ni tampoco lo contrario, una pura fabulación, mera inversión del platonismo sin más. Lo que pretende más bien es reconstruir el proceso por el cual la posibilidad de haber llegado a ser de un determinado modo, una posibilidad abierta al azar, se hace destino. De ahí nuestra traducción: Cómo llega uno a ser lo que es.

Más claramente inciden los cambios interpretativos cuando se trata de textos muy poco conocidos, ahora trabajados y anotados a fondo. Así, por ejemplo, aquella imagen tan parcial y esquemática del pensamiento del joven Nietzsche que lo reducía a las ideas de su primer libro, El nacimiento de la tragedia (y este, a su vez, a una estricta observancia de preceptos schopenhauerianos y wagnerianos) - una imagen cuestionable ya en buena medida a partir del material del volumen primero de Fragmentos Póstumos, donde las discrepancias con sus maestros afloran con frecuencia- se ve plenamente corregida por la luz que arrojan los escritos filosóficos de juventud correspondientes a los años 1865-1869, contenidos en el primer tomo de Obras Completas. Tal como agudamente señala Diego Sánchez Meca en el estudio introductorio a este volumen (OC I, espec. pp. 17-23), la recepción y reinterpretación de la Bildung clásico-romántica que Nietzsche lleva a cabo en esos años juveniles no solo implica una asimilación bastante crítica de las doctrinas de Kant y Schopenhauer por lo que hace a temas como la teleología en el primero o la metafísica de la voluntad en el segundo, sino también una especial empatía con una visión del universo como la de Demócrito, con la que la filosofía preplatónica habría venido a culminar su proceso de emancipación del mito. Esta predilección inicial del joven Nietzsche por una concepción científica como la democrítea, que prescinde de toda intervención divina para explicar el mundo, marca un hilo de continuidad con su recepción de la Historia del materialismo de Friedrich Albert Lange —clave de su temprana crítica a la equiparación schopenhaueriana de voluntad y «cosa en sí»— y con la adopción posterior de una actitud fuertemente escéptica en esa inflexión de su pensamiento representada por Humano, demasiado humano. De forma que lo que durante mucho tiempo apareció a ojos de los intérpretes de Nietzsche como una especie de conversión radical a una postura antimetafísica completamente novedosa, se descubre entonces como resultado de la reconquista de un punto de partida propio, independiente, anterior a su fascinación por Schopenhauer o Wagner. Asimismo, con consideraciones de esta índole se evidencia el problema de la periodización de la obra nietzscheana según la división tripartita tradicional, y 
la consiguiente necesidad de explorar más a fondo los encadenamientos entre su primera filosofía y la filosofía del espíritu libre.

Algo similar puede decirse respecto a lo que supone el conocimiento sistemático de la obra filológica de Nietzsche para la exégesis de su pensamiento filosófico. Desde luego, este conocimiento proporciona, de entrada, detalles de contenido que ayudan a cubrir algunas lagunas interpretativas y permiten una visión más acabada de su comprensión de la cultura griega. Además, algunas de las lecciones de Basilea nos brindan una imagen mejor perfilada de las correspondencias y contrastes entre el Nietzsche filólogo y el Nietzsche filósofo. Así ocurre, por ejemplo, en el caso del curso de Introducción al estudio de los diálogos platónicos (OC II, 441-562), que no solo nos muestra una dedicación de lo más minuciosa por parte del joven catedrático de filología clásica a los textos del propio Platón y a la literatura secundaria sobre él, sino una lectura bastante original y hasta cierto punto sorprendente del platonismo, casi coetánea a las tesis más antiplatónicas de El nacimiento de la tragedia. Por otra parte, la edición en castellano supone verdaderamente una contribución de primer orden, en la medida en que de textos como este suministra un muy completo aparato de notas - con localización de referencias, correcciones y aclaraciones- del que todavía carece la edición crítica alemana.

Pero sobre todo la obra filológica es importante porque permite entender mejor la génesis de los métodos y estrategias discursivas del pensar nietzscheano. Los escritos sobre retórica, por ejemplo, componen un jalón decisivo en las reflexiones de Nietzsche sobre el lenguaje, que desembocarán en la posición nominalista del ensayo Sobre verdad y mentira y sentido extramoral y, más tarde, en Más allá del Bien y del Mal, en el cuestionamiento de la común filosofía de la gramática de la que participa toda metafísica. Asimismo, su estudio de las fuentes antiguas, sus reflexiones metodológicas sobre la historia de la literatura griega y, más claramente, las consideraciones de su Enciclopedia de la filología clásica sobre hermenéutica y crítica (OC II, 297-312) constituyen una serie de aportaciones clave para reconocer en qué medida Nietzsche había venido haciendo «genealogía» desde mucho antes de haber acuñado ese filosofar histórico del que habla en los primeros aforismos de Humano, demasiado humano. La herencia del método histórico-crítico aprendido en la escuela de Pforta resulta decisiva al respecto. Pero también lo son los aportes posteriores de sus años de formación filológica en Bonn y Leipzig. En concreto, merecería la pena estudiar en profundidad cómo pudieron influir en Nietzsche métodos filológicos de crítica textual como el de Karl Lachmann, de quien recibió enseñanzas uno de sus principales maestros en la Universidad de Bonn, Otto Jahn. Además de como editor de Lucrecio, Homero o Propercio, Lachmann fue especialmente reconocido por acuñar un procedimiento para determinar la forma original de un texto a partir del examen de sus corrupciones: identificando por errores semejantes en distintos códices una rama común a todos ellos en un árbol genealógico (o stemma codicum), intentaba aproximarse a una variante lo más parecida posible al original. En cierto modo podría decirse, pues, que con su búsqueda de los orígenes de los valores morales y de la manera en que determinadas nociones (bueno, malo) habían sido corrompidas, devaluadas y reemplazadas por otras (Bien, Mal) a lo largo de la historia, la genealogía nietzscheana no hacía sino redimensionar un método practicado en aquellos tiempos en el ámbito de la filología. 
Como estamos viendo, para una comprensión histórico-evolutiva más precisa y exhaustiva del pensamiento nietzscheano, el conocimiento de los resultados del trabajo crítico-filológico de fijación de los textos, análisis de sus diferentes estratos de composición, datación, circunstancias, variantes, correcciones, registros de influencia, citas directas e indirectas y demás, resulta esencial. Ahora, gracias a las ediciones de los Fragmentos Póstumos, la Correspondencia y las Obras Completas, el lector en castellano puede establecer correlaciones entre los distintos momentos de esta trayectoria intelectual que antes permanecían ocultas para él y, sin negar la especificidad de cada uno de esos momentos, contemplarlos en una visión más integradora y plena de matices; puede hallar anticipaciones de algunas de las grandes ideas de madurez de la filosofía de Nietzsche en sus primeros escritos ${ }^{24}$, puede reconocer una complejidad mayor de la que se ha supuesto a menudo en el curso de su pensamiento ${ }^{25}$, y puede descubrir, en fin, nuevas líneas de lectura o influencias que hasta ahora habían pasado desapercibidas.

La ampliación de resonancias significativas dentro del nuevo horizonte interpretativo posibilitado por toda esta labor de edición ha servido a su vez para retroalimentar el cuidado técnico de los diferentes aspectos de la traducción, repasando y actualizando los resultados obtenidos. Ya nos hemos referido antes al trabajo preliminar de elaboración de un glosario de términos de ocurrencia frecuente en los escritos nietzscheanos. Parte de ese cometido preparatorio ha quedado reflejado en el índice terminológico y conceptual que aparece al final del cuarto y último volumen de Obras Completas, como complemento al conjunto de la edición. Pero de una forma mucho más esencial ha ido quedando plasmado a lo largo de toda la práctica traductológica desplegada por el equipo. La tarea de traducción representa ya, en sí misma, una actividad hermenéutica y un buen lector de Nietzsche —no digamos un buen traductor- no debería olvidarlo. Los integrantes de este proyecto no lo han hecho, poniendo a prueba y revisando la efectividad de sus propuestas. Basta con atender a las distinciones técnicas que introducen en sus notas críticas ${ }^{26}$, o a la manera en que, al ofrecer, en lugar de una simple traducción mecánica, puramente literal, una traducción interpretativa, que verdaderamente entiende lo que Nietzsche está diciendo, ayudan a aclarar el sentido de todo un texto o toda una línea de pensamiento ${ }^{27}$. El fino oído para la figura-

24. Por ejemplo, del pensamiento del eterno retorno en escritos como La filosofía en la época trágica de los griegos o Los filósofos preplatónicos; del tema del superhombre y la figura de Zaratustra, en la caracterización que del personaje de Empédocles hace Nietzsche en el esbozo de tragedia recogido dentro de los póstumos de 1872. En esa misma línea cabe reconocer la importancia de la lectura de Hölderlin en el joven Nietzsche, un autor apenas citado expresamente en la obra publicada (UB 1 y 2), pero bien presente por alusiones y citas implícitas en los póstumos.

25. Así, según indicamos antes, puede reconocer cómo la dirección antimetafísica que se expresa a partir de Humano, demasiado humano no supone una mera fase transitoria ni una simple reacción por la ruptura con Wagner, sino el reencuentro con motivos teóricos de su primera época.

26. Por ejemplo, entre «Sí mismo» (Selbst) y «yo» (Ich): Diego Sánchez Meca en FP III, 158; entre «instinto» (Instinkt) y «pulsión» o «impulso» (Trieb); entre «apariencia» (Schein) y «fenómeno» (Erscheinung): Joan Llinares, en OC I, 327 ss.; entre «cristianidad» (Christlichkeit) y «cristiandad» o «cristianismo» (Christentum); o también a propósito del neologismo «dys-angelium»: Llinares en OC IV, 738.

27. Un ejemplo, la nota 148 de la traducción de Jaime Aspiunza del libro De la genealogía de la moral: «das versprechen darf: 'que pueda prometer'; ahora bien, ese darf, de dürfen, es el poder del estar permitido. No me parece, por lo que Nietzsche va a desarrollar en este tratado, que la instancia 
ción musical del lenguaje nietzscheano, con continuas consonancias, aliteraciones, burlas, creaciones verbales y efectos sonoros, llena la traducción de felices hallazgos. El extenso trabajo colaborativo de documentación y contextualización hace además que entre los distintos traductores del equipo se mantenga la coherencia semántica de muchos términos, cuya especial connotación no siempre es fácilmente identificable. Se esclarecen así nociones que Nietzsche emplea a veces sin mayor precisión y cuyo significado técnico remite a lecturas o textos anteriores ${ }^{28}$. $\mathrm{O}$ bien se localiza toda una red de sentidos enlazados en torno a un vocablo o una expresión, prolongando la resonancia de su campo lexical en el conjunto de escritos nietzscheanos. Esto ocurre, de forma particularmente relevante, en el caso de la raíz leicht, que significa ligero, leve, y, en sentido figurado, fácil, carente de esfuerzo. Son muchos los juegos terminológicos efectuados por Nietzsche a partir de esta raíz. La emplea, por ejemplo, para hablar a menudo de Erleichterung (alivio, aligeramiento, desahogo), o cuando califica a la Tierra de die Leichte, la ligera, en Así habló Zaratustra. Como se explica en una nota de nuestra edición del segundo volumen de los Fragmentos Póstumos, creemos que un clave fundamental para todo el espectro semántico que el término recoge en los escritos de Nietzsche se halla en la referencia del fragmento 16 [8] de 1876 (FP, II, 236). Pues con la fórmula das leichte Leben, que aparece ahí, Nietzsche está traduciendo la expresión empleada por Homero para referirse a los dioses griegos como los rheia zoontes (Ilíada 6, 138; Odisea 4, 805), esto es, los que viven con facilidad, sin esfuerzo, aliviados de la pesadez, dificultad o carácter gravoso propio de la vida de los mortales. La vida de los dioses se muestra entonces como un puro vivir, es vida ligera, fácil o leve —e incluso, en buena medida, frívola y jovial一. Nietzsche se sirve de esa fórmula como modelo de una actitud no resentida ante la existencia, que tampoco se exige ya el pathos heroico algo afectado de El nacimiento de la tragedia, del cual se va a ir sintiendo cada vez más distante en las obras del llamado período intermedio. De lo que se trata es de aceptar la vida en su liviandad, sin ningún suplemento metafísico. Cuando Nietzsche habla, pues, de buscar un nuevo centro de gravedad y de afirmar el pensamiento del eterno retorno pese a que este pueda aparecer en principio como «la más pesada carga», sigue jugando en idéntico sentido con ese contraste entre el peso y la levedad que constituye, al decir de Milan Kundera, «la más misteriosa y equívoca de todas las contradicciones ${ }^{29}$. Y si tenemos en cuenta que poco después de la fecha del citado fragmento Nietzsche va a referirse a los espíritus libres designándolos igualmente como die Leichtlebenden, esto es, como aquellos que viven con facilidad, podemos ver cómo se produce aquí un cambio de temática, del análisis la cultura trágica de los griegos a la crítica de los prejuicios morales, que sin embargo mantiene un mismo ideario de fondo: la búsqueda de medios y actitudes capaces

permisora o permitente sea ni la ley ni el derecho, de ahí que no convenzan las propuestas de ASP, 'al que le sea lícito hacer promesas', o de JMS, 'al que le sea lícito prometer'. Lo traduciré, entonces, por 'puede permitirse prometer' (o, si cuadra mejor: 'hacer promesas'), en el buen entendido de que el original es siempre versprechen darf» (OC IV, 484).

28. Es el caso de la idea de un "pensar impuro", mencionada en varios fragmentos póstumos de 1875 y 1876, y que proviene de la lectura de El valor de la vida de Eugen Dühring.

29. M. Kundera, La insoportable levedad del ser, Barcelona: Tusquets, 1985, p. 13. Para la interpretación de esta idea, vid. M. Barrios, La voluntad de poder como amor, cit., pp. 132-160. 
de suscitar un sentimiento de aceptación de la existencia en su levedad e inconstancia, a diferencia de su condena metafísica y su rechazo nihilista. Así llegamos al término Erleichterung, que registra más de cien ocurrencias en los escritos nietzscheanos, con especial incidencia en las anotaciones preparatorias para $\mathrm{Hu}$ mano, demasiado humano, en La gaya ciencia y algunas obras de la última época. Se trata de una palabra a la que Nietzsche recurre a menudo para expresar la obtención de un estado de salud y equilibrio tras mitigar un dolor, desahogar una tensión o librarse de una carga opresiva (incluyendo a veces en su uso, de forma provocativa, las connotaciones propias de lo que supone «aliviar el vientre»). En los fragmentos póstumos de 1885 habla también de cómo los animales gregarios buscan una salida a su incapacidad de gobernarse a sí mismos y de cómo, en concreto, el cristianismo supuso para una Antigüedad desgarrada interiormente «el gran alivio» (FP III, 733). Y todavía en Humano, demasiado humano formula su caracterización de "los poetas como aliviadores (Erleichterer) de la vida» (MaM, I, 148) con ciertas reservas intelectualistas. Pero en los últimos escritos tiende a enfatizar el contraste entre esta Erleichterung, como un recurso fisiológicamente saludable, y el mecanismo enfermizo de la redención ascética. De esta manera, aunque considera que son nuestros «alivios» lo que tenemos que expiar más duramente (NW, OC IV, 918), Nietzsche se concede un pequeño «desahogo» al alabar a Bizet a expensas de Wagner (WA, Prólogo) y afirma reiteradamente que lo que persigue en la música es justo lo contrario a esa gravedad ascética sublimada de los acordes wagnerianos, esto es, su «aligeramiento» (FW 368 y NW ${ }^{30}$ ), «aligerar la vida» (FP 1886, 7 [7]). Vemos aquí, por tanto, cómo las traducciones de Aspiunza, Lavernia, Llinares, Sánchez Meca, Parmeggiani, Vermal y la mía, versionando diferentes matices del término alemán, lo que nos lleva a traducirlo a veces con distintos vocablos, mantienen una coherencia semántica en torno a un núcleo de significado y a una interpretación filosófica consecuente de fondo, que es lo que permite, sin entregarse a una polisemia caprichosa, potenciar la riqueza simbólica de la palabra en el sentido buscado por Nietzsche. Gracias al trabajo sistemático de revisión del glosario y al enfoque metodológico integrador adoptado por el equipo, esta ganancia de precisión en torno a un campo lexical se extiende además a nociones afines e interviene provechosamente en la localización de juegos de palabras que poseen una notable proyección teórica en el texto nietzscheano ${ }^{31}$. De esta forma, en fin, se ha ido consiguiendo tejer toda una red de correspondencias y nexos de sentido en la edición, que ha proporcionado una consistencia nada habitual a una labor de traducción realizada por un nutrido grupo de personas.

Para concluir este breve repaso de algunas virtudes de la nueva edición en castellano de las obras de Nietzsche, quisiéramos añadir una última consideración, relativa al hecho de que todos estos elementos de integración y este trabajo

30. «¿Qué es lo que quiere propiamente todo mi cuerpo de la música en general? Porque no hay alma... Creo que su aligeramiento: como si todas las funciones animales tuvieran que ser aceleradas con ritmos ligeros, atrevidos, desenvueltos y seguros de sí; como si esta vida férrea y plomiza tuviese que perder su pesadez por medio de melodías doradas y suaves como el aceite» (NW, OC IV, 907-908).

31. Es el caso, v.g., del juego verbal entre Last (carga) y Unlust (displacer), sobre el que agudamente llama la atención Killian Lavernia en una de las notas a su edición de Más allá del Bien y del Mal (OC IV, 315). 
colaborativo no solo han propiciado una mayor cohesión entre los miembros del equipo principal responsable del proyecto, sino que han permitido extender esta suerte de simpatía filosófica a sus muchos colaboradores puntuales - y, de modo muy especial, a representantes de la más joven y prometedora generación de estudiosos de la filosofía de Nietzsche de nuestro país, que se han formado en el seno de dicho proyecto y también han contribuido de manera sustantiva al resultado final ${ }^{32}$. Quisiéramos destacar, entre los más recientes, los nombres de Killian Lavernia e Inmaculada Hoyos. Ambos han preparado, bajo la supervisión de Diego Sánchez Meca, el material de complementos al conjunto de la edición en castellano de los Fragmentos Póstumos y las Obras Completas, que incluye una amplia relación de los instrumentos de trabajo empleados, un recuento de la historia de las ediciones, un índice de nombres propios y otro de términos y conceptos. Killian Lavernia se ha encargado asimismo de la traducción de Más allá del Bien y del Mal y de los Ditirambos de Dioniso. Además de estas aportaciones a la edición, Lavernia ya es autor de una espléndida tesis doctoral sobre La recepción del pensamiento de Nietzsche en la historia de sus ediciones, leída en 2017 en la UNED de Madrid. Por su parte, Inmaculada Hoyos, responsable del apartado referente a instrumentos de investigación, acaba de publicar un bello y sugestivo libro, cuyo hilo conductor, el contraste entre las pasiones que secundan la vida y las que la empobrecen, es de neta raigambre nietzscheana y spinoziana ${ }^{33}$. Como balance final de esta mirada sucinta a la reciente historia de la suerte de Nietzsche en castellano, podríamos exclamar por consiguiente, con las mismas palabras que un día nos dedicara, afectuosa y generosamente, Eugenio Trías en una carta en la que se refería a la manera en que habíamos incorporado la lectura de su obra a nuestro propio trabajo:

«Cómo me alienta esta continuidad en el país de la discontinuidad!» ${ }^{34}$.

32. Colaboraron en tareas de revisión Luis Chaparro, Laura Herrero, Inmaculada Hoyos, Jesús Martín, Sara Martínez, Óscar Quejido, Andrés Rubio, Bruno Roldán, Enrique Salgado y Eduardo Zazo. En tareas de traducción, Rafael Carrión, Killian Lavernia, Cristóbal Macías, Alejandro Martín y Jordi Redondo. Además, Antonio Morillas colaboró específicamente con Llinares en el apartado de notas de los fragmentos póstumos de otoño de 1887-enero de 1889, y David Mateo, José García Roca y Pascuala Sarrión en su revisión.

33. I. Hoyos, Sobre el amor y el miedo. Tópicos antiguos y enfoques modernos. Madrid: Avarigani, 2016.

34. En concreto, se trata de una carta de Eugenio Trías al autor del presente artículo, fechada en Barcelona, el 26 de julio de 1988, en la que Trías aprecia cómo nuestro trabajo recoge el testigo de sus propias cuestiones filosóficas a través del «arco tendido entre los fragmentos de Hölderlin y el fragmentarismo (y espantoso azar) de la clarividente visión nietzscheana» (folio 1). 